\title{
ATÉ QUE PONTO BRASIL E O MUNDO SE BENEFICIAM DE MEDIDAS DE ISOLAMENTO MAIS RÍGIDAS?
}

\section{ARTIGO DE REVISÃO}

SUETUGO, Isabela Moreira ${ }^{1}$

CARVALHO, Paula Bavaresco ${ }^{2}$

SUETUGO, Isabela Moreira. CARVALHO, Paula Bavaresco. Até que ponto Brasil e o mundo se beneficiam de medidas de isolamento mais rígidas? Revista Científica Multidisciplinar Núcleo do Conhecimento. Ano 05, Ed. 08, Vol. 01, pp. 87105. Agosto de 2020. ISSN: 2448-0959, Link de acesso: https://www.nucleodoconhecimento.com.br/saude/medidas-de-isolamento

\section{RESUMO}

A COVID-19 trouxe vários desafios em todo o mundo, um deles é a dificuldade em traçar estratégias eficazes que possam gerar uma redução na incidência dessa patologia, para que assim possamos ter maior controle na sua transmissão e letalidade. Muitos países optaram por medidas não farmacológicas devido ao fato de não possuirmos ainda terapias farmacológicas comprovadas cientificamente. O Brasil apresentou muitos obstáculos nas medidas de prevenção contra essa patologia, que vão desde conflitos políticos entre os níveis federal, estadual e municipal, até a não adesão da população. Ainda se sabe muito pouco sobre esse novo vírus, principalmente seu comportamento epidemiológico, o que conflita mais ainda suas estratégias de controle. Este estudo de revisão tem o intuito de analisar as medidas tomadas de isolamento social em diversos países, incluindo o Brasil, fazendo um comparativo entre quais seriam as melhores escolhas. Realizou-se uma pesquisa nos principais portais de estudos em saúde, buscando evidências recentes que pudessem

${ }^{1}$ Graduanda de medicina.

${ }^{2}$ Graduanda de medicina. 
gerar uma discussão sobre as vantagens e desvantagens das estratégias das principais potências mundiais que geraram estudos sobre isolamento social e confinamento total da população em detrimento da diminuição de casos de coronavírus. Há evidências que o isolamento social com confinamento total da população no início do surto tem melhor eficiência, apesar de alguns autores possuírem opiniões contrárias. Entretanto, não podemos deixar de lado que há uma problematização política, social e econômica na realização desta medida que ainda gera debates entre os governantes, profissionais da saúde e a população.

Palavras-chave: COVID-19, coronavírus, isolamento social, lockdown.

\section{INTRODUÇÃO}

A COVID-19 (Coronoavirus disease-19) é uma patologia emergente que desde sua disseminação vem causando danos a população de diversos países. É caracterizada com uma doença que atinge principalmente o sistema respiratório, ocasionando febre e/ou tosse e dificuldade respiratória, com 1/3 dos pacientes evoluindo com Síndrome Respiratória Aguda Grave. Pode apresentar outros sintomas inespecíficos como mialgias, cefaleia, confusão mental, dor torácica e diarreia. Os primeiros casos surgiram na cidade de Wuhan, na província de Hubei, na China, no início de dezembro de 2019. Somente em 7 de janeiro de 2020 foi identificado como um novo coronavírus, sendo denominado como 2019-nCov pela OMS (Organização Mundial de Saúde). O vírus ainda tem um comportamento epidemiológico desconhecido, uma vez que as taxas de letalidade aparentam ter muita variabilidade, sendo na Itália $9 \%$ e na Alemanha $0,3 \%$. Mas, sabe-se que há muitos fatores de risco que podem influenciar nessas taxas, como a doença pulmonar obstrutiva crônica, diabetes, obesidade e hipertensão arterial sistêmica. Somente no dia 11 de março de 2020 a OMS declarou a pandemia global, com contagem confirmada em todo mundo de 118.000 casos em 114 países, com um número de óbitos próximo a 4.200. No final de abril a pandemia atingiu 213 países tendo mais de 3 milhões de casos confirmados, mostrando o grande impacto que a doença tem em âmbito mundial (OMS, 2020). 
O Brasil encontra-se em segundo lugar no ranking de países com mais casos confirmados no mundo com mais de 1,5 milhões de casos, perdendo somente para os Estados Unidos da América que possui mais de 2,7 milhões de casos. Nota-se também, pelo gráfico fornecido pela Universidade de Oxford, que o Brasil é seguido respectivamente pela Índia com mais 1,1 milhões, a Rússia com mais de 650.000 e a África do Sul com mais de 270.000 casos, o que mostra uma grande distância no número de casos novos do Brasil em comparação como mundo (ANEXO 1).

Ainda sobre as características desse patógeno, foi evidenciado que sua disseminação ocorre particularmente por gotículas respiratórias. O vírus se aloja nas secreções respiratórias do indivíduo infectado que ao espirrar, tossir ou falar, as gotículas provenientes das vias respiratórias dessa pessoa podem chegar até a via respiratória de outra pessoa, contaminando-a. Outra forma de transmissão é pela superfície de objetos, ao tocar em um objeto contaminado e após ter contato com nariz, olhos ou boca. Inclusive, existe a transmissão por aerossóis depois de realizar procedimentos de nebulização ou intubação orotraqueal (VELASCO et al., 2020).

Devido à ausência de imunidade prévia na população humana e vacina contra o patógeno, o número de casos aumentou drasticamente. Dentro desta ótica, os epidemiologistas propuseram, como forma de impedir a propagação do vírus, as intervenções não farmacológicas, impondo medidas que pudessem impedir o contágio dos cidadãos, sendo desde lavagem de mãos até fechamento de fronteiras com isolamento social (GARCIA; DUARTE, 2020). A Organização Pan-Americana de Saúde (OPAS) lançou uma nota no dia 3 de abril de 2020, favorável às medidas não farmacológicas. A nota sugere que essas medidas possam, além de achatar a curva epidêmica, aliviar o colapso dos serviços de saúde, principalmente nas unidades hospitalares de cuidados intensivos. Dentre as medidas não-farmacológicas temos o confinamento total (lockdown), o distanciamento social seletivo e o distanciamento social ampliado, que são medidas de distanciamento entre as pessoas, a fim de conter a transmissão entre elas. Segundo Nakamura (2020, p.3)

O lockdown é o nível mais alto de segurança e pode ser necessário em situação de grave ameaça ao sistema de saúde. Durante um bloqueio 
total, todas as entradas do perímetro são bloqueadas por profissionais de segurança e ninguém tem permissão de entrar ou sair do perímetro isolado. Difere das demais medidas de distanciamento social, tais como o distanciamento social ampliado, conhecido como quarentena, e o distanciamento social seletivo, conhecido como isolamento vertical. O distanciamento social ampliado é uma medida de distanciamento social que não é limitada a grupos específicos, exigindo que todos os setores da sociedade permaneçam na residência durante a vigência da decretação da medida pelos gestores locais. Esta medida restringe ao máximo o contato entre pessoa. O distanciamento social seletivo é o distanciamento social onde apenas alguns grupos ficam isolados, sendo selecionados os grupos que apresentam mais riscos de desenvolver a doença ou aqueles que podem apresentar um quadro mais grave, como idosos e pessoas com doenças crônicas (diabetes, cardiopatias etc.) ou condições de risco como obesidade e gestação de risco. Pessoas abaixo de 60 anos podem circular livremente, se estiverem assintomáticos.

Segundo a OPAS (2020), ainda há medidas como isolamento de pessoas, que é a separação dos portadores da doença objetivando a não transmissão, e a quarentena de pessoas, que restringe as atividades e separa as pessoas não doentes a fim de evitar o aparecimento de novos pacientes infectados. As medidas mais drásticas, como o confinamento domiciliar, foram indicadas pela OPAS em "segmentos selecionados", como por exemplo, para a população de idosos, pessoas com maior risco de desfecho fatal, ou a população em sua totalidade, quando há contextos legais, administrativos e sanções que permitam esse tipo de atividade. Este confinamento pode ser feito com o estabelecimento de medidas de toque de recolher ou a limitação da movimentação das pessoas dentro de um perímetro pré-definido, sendo permitida a saída somente para fins médicos e tarefas domésticas de subsistência.

Todavia, essas medidas de isolamento social e, até mesmo, confinamento total da população apresentam muitos problemas, tais como déficits na estrutura social e, principalmente, econômica de muitos países, como traz a atualização da nota de 3 de abril de 2020 pela OPAS que foi lançada dia 24 de abril de 2020. A atualização evidenciou inúmeros questionamentos por parte dos governantes quanto às adoções de "medidas severas de distanciamento social e medidas relativas a viagens" e o documento teve como objetivo sanar essas dúvidas e guiar as tomadas de decisões dos dirigentes que citaremos adiante na discussão do artigo. 
No dia 3 de fevereiro de 2020 foi declarada a epidemia no Brasil, sendo considerada emergência em saúde pública, e no dia 6 de fevereiro de 2020 foi sancionada a Lei no 13.979, que determina as medidas de enfrentamento da epidemia do COVID-19, além de atribuir estratégias supostamente eficazes de intervenções não farmacológicas (GARCIA; DUARTE, 2020). Contudo, o Brasil, da mesma forma como outros países latinos, sofre muitos obstáculos, como a não conscientização da população quanto ao isolamento, falta de infraestrutura nas unidades de saúde do país, um alto desnivelamento social e dificuldades em traçar uma linearidade em suas medidas de enfrentamento da doença, posto que cada estado e cidade tiveram posturas diferentes quanto a pandemia. Muitos questionamentos ocorreram sobre a legalidade da realização de um confinamento obrigatório, que pode infringir o direito de ir e vir do ser humano (BEZERRA et al., 2020). Todo esse contexto gera uma grande discussão sobre as reais vantagens na realização de atividades tão severas como essas.

\section{OBJETIVOS}

O objetivo do presente estudo foi analisar as vantagens e desvantagens do lockdown e comparar as estratégias realizadas em âmbito mundial e nacional. Objetivando a melhor análise atual sobre as estratégias de prevenção e diminuição da taxa de incidência no mundo.

\section{METODOLOGIA}

Para a realização do presente estudo foram pesquisados 26 fontes dentre artigos na língua portuguesa e inglesa, livros e fontes de dados epidemiológicos mundiais e nacionais, utilizando bases de dados nacionais e internacionais: MEDLINE/PubMed, Scielo, The Lancet, Natural Medicine, site de busca da Organização Mundial da Saúde e no site de busca Google Acadêmico. As palavras-chaves utilizadas para a seleção dos artigos foram: "lockdown"; "covid-19"; "coronavírus; "isolamento social"; "epidemia"; e "controle".

Após levantamento bibliográfico foi feita leitura exploratória, por dois pesquisadores, dos artigos selecionados da área de saúde coletiva e epidemiológica para identificar 
aqueles de possível interesse para a construção do trabalho, embasando-se nas escolhas dos artigos mais recentes e que tratassem do tema de forma a ser comprovada cientificamente por métodos reais. Em seguida foi realizada uma leitura seletiva e aprofundada identificando os de conteúdo realmente relevante para a elaboração desta revisão.

\section{DISCUSSÃO}

Procuramos por artigos que pudessem evidenciar as vantagens e desvantagens de um confinamento mais rigoroso como o lockdown. Um debate promovido pelo site The BMJ (2020) e mesmo havendo muitos fatores que indiquem ao lockdown como boa alternativa, há autores que divergem desta opinião. A pesquisa mostra que, de início, é uma boa estratégia, mas em bloqueios prolongados há um déficit econômico relevante, gerando altas taxas de desemprego, por exemplo (TODA MATÉRIA, 2020). Martin et al. (2020) evidencia as graves perdas agudas da economia do mundo devido as medidas de distanciamento social. Cita um relatório do Banco Mundial demonstrando que 11 milhões de pessoas poderiam cair abaixo da linha da pobreza no leste da Ásia e no Pacífico, além de evidenciar a queda do produto interno bruto (PIB) da maior potência mundial, Estados Unidos da América, em 4,8\% no primeiro trimestre de 2020. O artigo ainda alerta sobre os cuidados que os países devem demonstrar, como o desemprego em alta escala, aumento da necessidade de recursos para a saúde pública, alto índice de pobreza mundial e longo tempo para recuperação econômica de países subdesenvolvidos.

Além dos desafios econômicos, também surgiram muitos problemas em saúde com a realização de um bloqueio. Um artigo publicado pela The Lancet (2020) em 4 de julho de 2020, demonstrou desapontamento por parte dos autores na dicotomia que existe na ideia do fechamento do comércio e no isolamento social. $\mathrm{O}$ artigo refere que a UNICEF e os autores acreditam que os bloqueios possam matar pessoas através da interrupção de serviços de saúde e privação de meios de subsistência, afirmando que as populações que vivem à margem da economia se beneficiam pouco do bloqueio, $\mathrm{e}$ as crianças são as mais expostas a tal vulnerabilidade. Nos países em desenvolvimento do continente africano foi notada muita dificuldade de comunicação 
com a população, que ocorre desde a epidemia de Ebola e HIV e permanece até hoje, devido a uma heterogeneidade da população etnias, culturas e hábitos (JOHNSON e GORONGA, 2020). A respeito de crianças e adolescentes, o artigo de Knopf (2020), publicado no Jornal da Academia Americana de Psiquiatria da Criança e do Adolescente, há maior possibilidade de aumento dos distúrbios psiquiátricos, em crianças e adolescentes, ao longo do período de quarentena, uma vez que o fechamento das escolas gerou um isolamento social de jovens, deixando-os mais solitários. Além disso, também foi evidenciado pelo artigo multinacional de Roso et al. (2020), que analisou os adolescentes em isolamento social na Itália, Espanha, Chile, Colômbia e Brasil, um aumento dos maus hábitos alimentares dos adolescentes, aumentando o risco subsequente de doenças metabólicas e degenerativas.

No Brasil, surgiram vários desafios a serem superados, assim como nos outros países, desde a falta de escolarização da população, problemas de desemprego e estresse psicológico, como foi evidenciado na pesquisa de Garcia e Duarte (2020). O governo federal brasileiro, com sua política voltada a economia, difundiu a ideia de um Brasil que não pode parar, incentivando a manutenção do fluxo de pessoas nas ruas e no seguimento das atividades do comércio. Este discurso veio em contraponto às medidas tomadas, principalmente em alguns entes federativos como São Paulo, epicentro da doença, com isolamento social mais rígido. Essas divergências de diálogos e conflitos políticos pioraram ainda mais o quadro da pandemia, sendo agravado por uma disputa política e aparecimento de notícias falsas que foram difundidas pelos meios de comunicação e redes sociais. Isso dificultou muito a adesão da população ao isolamento e ao distanciamento, afetando diretamente no cumprimento por parte da população (AQUINO, 2020). Ademais, houve ampla discussão se o lockdown teria respaldo legalmente constituído, uma vez que pode infringir o direito de ir e vir do cidadão. Como é citado no artigo de Nakamura (2020) o lockdown deve ser visto como um instrumento de proteção da saúde e da vida das pessoas. Entretanto, ele limita de forma intensa um direito fundamental de locomoção previsto no art. 5o, inciso XV da Constituição nos seguintes termos: "é livre a locomoção no território nacional em tempo de paz, podendo qualquer pessoa, nos termos da lei, nele entrar, permanecer ou dele sair com seus bens". A liberdade de 
locomoção abrange a liberdade de locomoção propriamente dita e a de circulação. Conforme lição de José Afonso da Silva "a liberdade de locomoção no território nacional em tempo de paz, contém o direito de ir e vir (viajar e migrar) e de ficar e de permanecer, sem necessidade de autorização". Já o direito de circulação, ainda segundo José Afonso da Silva, "consiste na faculdade de deslocar-se de um ponto a outro, através de uma via pública afetada ao uso público".

No entanto, as desvantagens apontadas acima são contrabalanceadas por outras soluções. Até mesmo o artigo de Martin et al. (2020), que apresenta pontos extremamente negativos sobre o confinamento, mostra que a COVID-19 sem nenhuma proteção levaria a um choque econômico maciço no sistema e, de fato, há formas de evitar piora do quadro econômico, como foi a implementação da Lei CARES (Lei de Auxílio ao Coronavírus, Socorro e Segurança Econômica) sancionada nos EUA dia 27 de março de 2020 pelo presidente Trump, auxiliando 90\% dos desempregados financeiramente. Além disso, todos os artigos citados nos parágrafos acima desta discussão não denotam certeza nos dados, deixando notório que seriam "possibilidades".

Podemos ver artigos que apontam outros pontos positivos do lockdown em países que aderiram à medida. Na Itália e Espanha, países que foram intensamente atingidos pela doença, foram evidenciados que, após o confinamento, houve uma grande redução na incidência da doença, levando um achatamento real na curva epidemiológica desses países (TOBIAS, 2020). Em particular na Itália, há evidência de que as restrições de contato surtiram efeito na diminuição da incidência em nove dias nos locais de maior prevalência, apresentando efeitos em média de 14 a 18 dias de modo geral no país (VINCETI et al., 2020). Já em outros países europeus, a Grécia, mesmo ainda não tendo se estabilizado economicamente, foi um dos países que aderiram ao lockdown que melhor se destacou, conseguiu um achatamento da curva de casos novos sem que agravasse mais a situação instável do sistema de saúde do país e gerasse grandes déficits econômicos. Ademais, ficou somente após a Noruega e a Finlândia nos menores números de óbitos por milhão de habitantes, devido ao investimento maciço no sistema de saúde que estas duas últimas fizeram (MORIS; 
SCHIZAS, 2020). Outro estudo realizado no Reino Unido, país também muito afetado pela COVID-19, calculou que houve alto nível de aceitação às medidas de isolamento tomadas pelo governo e resultou numa diminuição de $74 \%$ no número total de contatos físicos, e não físicos, por pessoas, e esta restrição de contato propiciará uma redução da incidência, mesmo que não imediata (JAVIS et al., 2020).

Em relação ao continente asiático, no epicentro da pandemia em Wuhan, notou-se uma diminuição da exponencial de crescimento dos casos novos. Contudo, fora da área de bloqueio a incidência continuou aumentando, atribuindo ao bloqueio um sinal positivo para retardar o contágio de novos indivíduos (LAU et al., 2020). Foi possível reafirmar que os afrouxamentos das medidas preventivas geraram aumento de $71,8 \%$ no número de casos novos, pelo artigo de Hussein et al. (2020), com o afrouxamento das medidas em Israel, que mesmo não sendo no mesmo continente, evoluiu com o mesmo histórico. A exemplo de um país subdesenvolvido, em artigo publicado pela Revista de Infecções no Países em Desenvolvidos, a Índia realizou um bloqueio prolongado de 19 dias, seguido de bloqueios menores de até 14 dias, com certos relaxamentos, e conseguiu diminuir relativamente os casos novos e a mortalidade por milhão de habitantes (KRISHAN e KANCHAN, 2020). Outro artigo da Índia evidenciou, por meio de uma metodologia matemática, que realmente surtiram efeitos positivos os confinamentos e, até mesmo sugere, que o bloqueio seja feito 21 dias em todo o país e uma extensão de mais 21 dias melhoraria a interrupção na transmissão em cadeia (AMBIKAPATHY e KRISHNAMURTHY, 2020).

Ainda falando de países em desenvolvimento, o continente africano já enfrentou uma epidemia de um vírus pouco conhecido na época, o Ebola, há aproximadamente 6 anos e ainda enfrenta uma epidemia de HIV. Essas experiências trouxeram muitos ensinamentos aos países deste continente, como, por exemplo, o Zimbábue e a SerraLeoa que necessitaram altos investimentos na conscientização da população para que as medidas de prevenção fossem mais eficazes e trouxessem menos prejuízos a esses países que já vivem em situação de marginalidade social e econômica. Esse estudo também mostrou que é possível realizar estratégias que aproximem a 
população de uma conscientização plena sobre a necessidade de prevenção, em meio a falta de recursos desses países (JOHNSON e GORONGA, 2020).

Em se tratando dos problemas saúde mental, o artigo de Matias et al. (2020) não nega que o isolamento tenha efeitos nocivos à saúde mental, contudo, há estratégias que podem melhorar esses danos, como por exemplo a atividade física, mesmo realizada em isolamento social, que também propiciaria uma diminuição dos fatores de risco cardiovascular. Ademais, o estudo de Hoffman et al. (2020), demonstra de forma científica que podemos propor três diferentes estratégias simples para aliviar os encargos sociais, psicológicos e econômicos ao longo da pandemia, como por exemplo: busca de similaridade (os indivíduos devem buscar semelhanças em contatos que tenham assuntos e características que atraiam sua atenção, como forma de reestruturação de uma rede de contatos), fortalecimento de interações nas comunidades (os indivíduos devem interagir de forma triádica, fazendo com que seu contato seja o mesmo que o de seu amigo, para que isso fortaleça um diálogo entre esse grupo), e interação repetida com as mesmas pessoas para criar bolhas (essas redes estreitas propiciam um contato menor com indivíduos, seria indicado para pessoas idosas ou com fatores de risco pré-existentes, para que limitem o contato com pessoas que possivelmente possam transmitir a doença).

No Brasil, segundo o Datafolha que entrevistou uma amostra de 1.511 pessoas em abril de 2020 em diversos estados, 76\% da população mostrou-se favorável a manutenção do distanciamento social, provando que a população se interessa em medidas não farmacológicas (AQUINO et al., 2020). Além disto, pelos dados coletados pelas Secretarias Estaduais de Saúde, a curva de incidência ainda se apresenta crescente (ANEXO 2), mas no estado de São Paulo, notou-se um leve achatamento da curva nas últimas semanas, o que pode, ou não, se referir ao isolamento feito pelo poder público, mesmo com as divergências de condutas em relação ao governo federal.

Ainda sobre o confinamento e as questões que surgiram sobre sua permissão legal no Brasil o artigo de Nakamura (2020, p.5) diz que: 
O direito de locomoção pode ser restringido mesmo em tempo de paz, desde que exista outro direito fundamental a ser protegido mediante a implantação de uma medida restritiva da locomoção das pessoas, tal como para evitar a expansão de uma pandemia. Conforme entendimento do Supremo Tribunal Federal, "não há direito absoluto à liberdade de ir e vir (CF, art. 5o, XV) e, portanto, existem situações em que se faz necessária a ponderação dos interesses em conflito na apreciação do caso concreto13" [...] Existe a denominada "polícia sanitária", fundada no inciso II do art. 200 da Constituição Federal, que deve ser exercido pela União, Estados, Distrito Federal e Municípios, em razão do art. 23, II, da Constituição Federal. Se, em razão do estágio da pandemia, mediante fundamentação comprovada em estudos técnicos, for necessária a decretação do lockdown, como a medida de polícia sanitária mais adequada e eficiente, podem os Estados e Municípios o decretarem. Se o estágio da epidemia que justifique a medida mais restritiva estiver contida dentro do território de um município, este deve decretar o lockdown; caso tenha ultrapassado o âmbito de um município, deve o Estado decretar o lockdown; e, por fim, caso tenha ultrapassado o âmbito de um Estado, deve a União decretar o lockdown.

Desta forma, pode-se concluir que mesmo ferindo o direito de ir e vir do cidadão, ainda é dever do Estado cuidar de sua saúde, podendo ser decretado o lockdown. Também, nas considerações dadas pela OPAS sobre distanciamento social e restrições relativas às viagens, foi sugerido que este confinamento seja feito com aplicações de ferramentas legais, criando medidas administrativas que possam sancionar apoio legal para tal atitude, avaliando a adequação legal

\section{CONCLUSÃO}

A doença, por ser emergente e de rápida expansão, traz grandes dificuldades em delinear os dados estatísticos, impedindo e retardando muitos processos de prevenção. Em âmbito mundial, a doença tornou-se agravante na maioria dos países e surtiu efeitos drásticos, principalmente à economia. Houve muitas diferenças na maneira de realização do isolamento entre os países. O que tornou mais difícil ainda traçar planos efetivos e seguros para a realização de um confinamento efetivo.

Contudo, muitos países concordam que a melhor estratégia são as medidas não farmacológicas, principalmente devido à falta de tratamento específico e vacinas eficazes. É claro que não podemos deixar de falar dos problemas em saúde que o 
isolamento causa na sociedade, mas pudemos evidenciar, em vários artigos, que a instrução da comunidade associada ao investimento e apoio à saúde da população, pelo poder público, podem ser formas eficazes evitando maiores danos causados pelo coronavírus e o distanciamento social. Essas estratégias proporcionam maior adesão por parte dos governantes à aceitação de uma estratégia mais rígida de isolamento, já que mesmo com os prejuízos econômicos, não há como contestar que o confinamento social diminui a curva de incidência da doença.

No Brasil, os desafios internos do país, como por exemplo as divergências políticas entre os níveis municipais, estaduais e federal, comprometem mais ainda o controle da taxa de incidência da doença. No entanto, não podemos deixar de notar que outros países em desenvolvimento e tão populosos quanto o Brasil, como a Índia e a China, se beneficiaram do lockdown. A Índia é um exemplo atual, o país indiano conseguiu ficar com menos casos acumulados do que o Brasil, ocupando a terceira posição no ranking, mesmo com uma população de 1,3 bilhões de habitantes em comparação aos 209,5 milhões de habitantes que o Brasil possui, segundo o Banco Mundial. Mesmo que haja casos de subnotificação, ainda podemos evidenciar a diferença entre esses dois países nos dados de casos novos.

Para concluir, em muitos países foi fundamental a adoção de estratégias rígidas de isolamento social, para o sucesso no controle desta pandemia de coronavírus. No entanto, o lockdown deve ser planejado e executado de forma muito bem planejada, considerando o aspecto demográfico e epidemiológico. Há evidências, nas pesquisas, que países que mais tiveram sucesso, foram aqueles que se planejaram previamente e buscaram evitar conflitos internos, como o caso da Noruega (alto investimento em saúde) e dos países africanos (alto investimento em estratégias que aproximem a população da aceitação às medidas preventivas) . É nítido, também, que há outros fatores que interferem na taxa de incidência, mas o impedimento da transmissão com medidas não farmacológicas, mostra-se uma estratégia eficaz de baixo custo ao governo (que permite até os países marginalizados aderirem a prática). E até que não existam formas farmacológicas consistentes e específicas que possam diminuir a incidência da doença, esta é uma estratégia que pode ser seguida por diversos países. 


\section{REFERÊNCIAS}

AMBIKAPATHY, B.; KRISHNAMURTHY, K. Mathematical modellind to assess the impact of lockdown on COVID-19 transmission in India: Model development and validaton. Departament of Instrumentation Engineering, Madras Institute of Technology Campus, Chennai, Tamil Nadu, India, 7 de maio de 2020, v. 6, n. 2. Disponível em: <https://publichealth.jmir.org/2020/2/e19368/>. Acesso em: 28 de julho de 2020.

AQUINO, E. M. L. et al. Medidas de distanciamento social no controle da pandemia de COVID-19: potenciais impactos e desafios no Brasil. Ciência e Saúde Coletiva, 5 de junho de 2020. Disponível em: <https://www.scielosp.org/article/csc/2020.v25suppl1/2423-2446/pt/ >. Acesso em: 28 de julho de 2020.

BEZERRA, A. C. V. et al. Fatores associados ao comportamento da população durante o isolamento social na pandemia de COVID-19. Ciênc. Saúde coletiva, v. 25, Rio de Janeiro, Brasil. Disponível em: $<$ https://www.scielo.br/scielo.php?script=sci_arttext\&pid=S1413$81232020006702411 \&$ tIng=pt>. Acesso: 26 de junho de 2020.

CDC European. Casos acumulados de COVID-19. Dos dia 19 de janeiro de 2020 ao dia 28 de julho de 2020. Disponível em: <https://ourworldindata.org/coronavirus-dataexplorer?yScale=log\&zoomToSelection=true\&minPopulationFilter $=1000000 \&$ casesM etric=true\&totalFreq=true \&aligned=true \&hideControls=true\&smoothing $=0 \&$ country $=\&$ pickerMetric=location\&pickerSort=asc $>$. Acesso em: 28 de julho de 2020

GARCIA, L. P.; DUARTE, E. Intervenções não farmacológicas para o enfrentamento à epidemia da COVID-19 no Brasil. Epidemiol. Serv. Saúde, Brasília, Brasil, v. 29, n. 2, e. 2020222, 2020 . Disponível em: <http://www.scielo.br/scielo.php?script=sci_arttext\&pid=S223796222020000200100\&lng=en\&nrm=iso $>$. Acesso: 26 de junho de 2020. 
HOFFMAN, M. et al. Estratégias de distanciamento baseadas em redes sociais para nivelar a curva COVID-19 em um mundo pós-bloqueio. Nat Hum Behav, 4 de junho de 2020, v.4, p. 588-596. Disponível em: <https://doi.org/10.1038/s41562-0200898-6>. Acesso 28 de julho de 2020.

HOU, Z. et al. Cross-country comparison of public awareness, rumours, and behavioural responses to the COVID-19 epidemic: An internet surveillance study. Journal of Medical Internet Research, 6 de junho de 2020. Disponível em: $<$ https://s3.ca-central-1.amazonaws.com/assets.jmir.org/assets/preprints/preprint21143-accepted.pdf>. Acesso em: 28 de julhode 2020.

HUSSIEN, N. R. et al. A sharp increase in the number od COVID-19 cases and case fatality rates after lifiting the lockdown in Kurdistan region of Iraq. Annals od Medicine and Surgery, Setembro de 2020, v.57, p. 140 - 142. Disponível em: < https://www.sciencedirect.com/science/article/pii/S2049080120302120?via\%3Dihub> . Acesso em: 28 de julho de 2020.

IBARRA-VEGA, Danny. Lockdown, one, two, none, or smart. Modeling containing covid-19 infection. A conceptual model. Science of the total environment, v. 730, August 2020, n. 138917. Disponível em: <https://www.sciencedirect.com/science/article/pii/S0048969720324347?via\%3Dihub >. Acesso em: 26 de junho de 2020.

JAVIS, C. I. et al. Quantifying the impact of physical distance measures on the transmission of COVID-19 in the UK. BMC Medicine, 7 de maio de 2020, n. 124. Disponível em:< https://bmcmedicine.biomedcentral.com/articles/10.1186/s12916020-01597-8>. Acesso em: 28 de julho de 2020.

JOHNSON, O.; GORONGA, T. Why communities must be at the centre of Coronavirus disease 2019 response: Lessons from Ebola na Human immunodeficienty virus in Africa. African Journal of Primay Health Care \& Family Medicine, 22 de junho de 2020. Disponível em: 
<file://C:/Users/caezi/Downloads/2496-27472-1-PB.pdf>. Acesso em: 28 de julho de 2020.

KNOPF, A. Prepare for increased depression, anxiety in youth due to COVID-19 lockdown. Wiley Online Library, 24 de julho de 2020. Disponível em: <https://onlinelibrary.wiley.com/doi/abs/10.1002/cpu.30511>. Acesso em: 28 de julho de 2020.

KRISHAN, K.; KANCHAN, T. Lockdown is a effective 'vacine' gainst COVID-19: a messagem from India. The Journal of Infection in Developing Countries, 6 de junho de 2020, v. 14. Disponível em: <https://jidc.org/index.php/journal/article/view/12931>. Acesso em: 28 de julho de 2020.

LAU, $\mathrm{H}$. et al. The positive impact of lockdown in Wuhan on containing the COVID-19 outbreak in China. Journal of Travel Medicine, v. 27, ed. 3 de abril de 2020. Disponível em: <https://academic.oup.com/jtm/article/27/3/taaa037/5808003>. Acesso: 1 de julho de 2020.

MARTIN, A. et al. Socio-economic impacts of COVID-19 on household consumption em poverty. 23 de julho de 2020. Disponível em: $<$ https://link.springer.com/article/10.1007/s41885-020-00070-3>. Acesso em: 28 de julho de 2020.

MATIAS, T, DOMINKIi, F.H., MARKS, D.F. (2020) Human needs in COVID-19 isolation. Journal of Health Psychology, 6 de maio de 2020. Disponível em: $<$ https://journals.sagepub.com/doi/10.1177/1359105320925149>. Acesso em: 28 de julho de 2020.

MELNICK, E. R; IOANNIDIS, J. P A. Should governments continue lockdown to slow the spread of covid-19? BMJ 2020; v.369. Disponível em: <https://www.bmj.com/content/369/bmj.m1924.long>. Acesso: 3 de julho de 2020. 
MORIS, Dimitrios; SCHIZAS, Dimitrios. Lockdown during COVID-19: The Greek success. In Vivo, v. 34, ed. n. 3, p. 1695 - 1699, 2020. Disponível em: <http://iv.iiarjournals.org/content/34/3_suppl/1695.long> Acesso: 1 de julho de 2020.

NAKAMURA, A. L. S. A possibilidade de decretação do "lockdown" pelos Estados em razão da Covid-19. São Paulo, Brasil. Disponível em: $<$ https://preprints.scielo.org/index.php/scielo/preprint/view/551/723>. Acesso: 3 de julho de 2020.

NETO, R. A. B. Infecção pelo vírus Influenza e coronavírus (COVID-19). In: VELASCO, I. T. et al. Medicina de Emergência: Abordagem Prática. 14.ed. São Paulo: Editora Manole, 2020. Cap. 57, p. $717-728$.

ORGANIZAÇÃO PAN-AMERICANA DE SAÚDE. Considerações sobre medidas de distanciamento social e medidas com as viagens no contexto da resposta à pandemia de COVID-19. 3 de abril de 2020. Disponível em: < https://iris.paho.org/bitstream/handle/10665.2/52045/OPASBRACOVID1920039_por. pdf?sequence=9 >. Acesso em: 28 de julho de 2020 .

ORGANIZAÇÃO PAN-AMERICANA DE SAÚDE. Considerações sobre ajustes das medidas de distanciamento social e medidas relativas a viagens no contexto da resposta à pandemia de COVID-19. 24 de abril de 2020. Disponível em: < https://iris.paho.org/bitstream/handle/10665.2/52045/OPASBRACOVID1920039a_\% 20por.pdf?sequence=8 >. Acesso em: 28 de julho de 2020 .

RUIZ-ROSO, M.B. A. Covid-19 Confinement and Changes of Adolescent's Dietary Trends in Italy, Spain, Chile, Colombia and Brazil. Nutrients 2020, n12, p.1807. Disponível em: <https://www.mdpi.com/2072-6643/12/6/1807\#cite>. Acesso em: 28 de julho de 2020.

THE LANCET. Lockdown is not egalitarian: the costs fall on the global poor. 19 de julho de 2020 Disponível em: <https://www.thelancet.com/action/showPdf?pii=S0140-6736\%2820\%2931422-7>. Acesso em: 28 de julho de 2020. 
TOBÍAS, A. Evaluation of the lockdowns for the SARS-CoV-2 epidemic in Italy and Spain after one month follow up. Sci. Total Environ., v.725, artigo 138539, 2020. Disponível em: <https://www.sciencedirect.com/science/article/pii/S0048969720320520?via\%3Dihub >. Acesso: 1 de julho de 2020.

VINCETI, M. et al. Lockdown timing and efficacy in controlling COVID-19 using mobile phone tracking. EcClinical Medicine, 13 de julho de 2020. Disponível em: $<$ https://www.thelancet.com/journals/eclinm/article/PIIS2589-5370(20)302017/fulltext>. Acesso em: 28 de julho de 2020.

\section{ANEXOS}

\section{ANEXO 1}

Cumulative confirmed COVID-19 cases

The number of confirmed cases is lower than the number of actual cases; the main reason for that is limited testing.

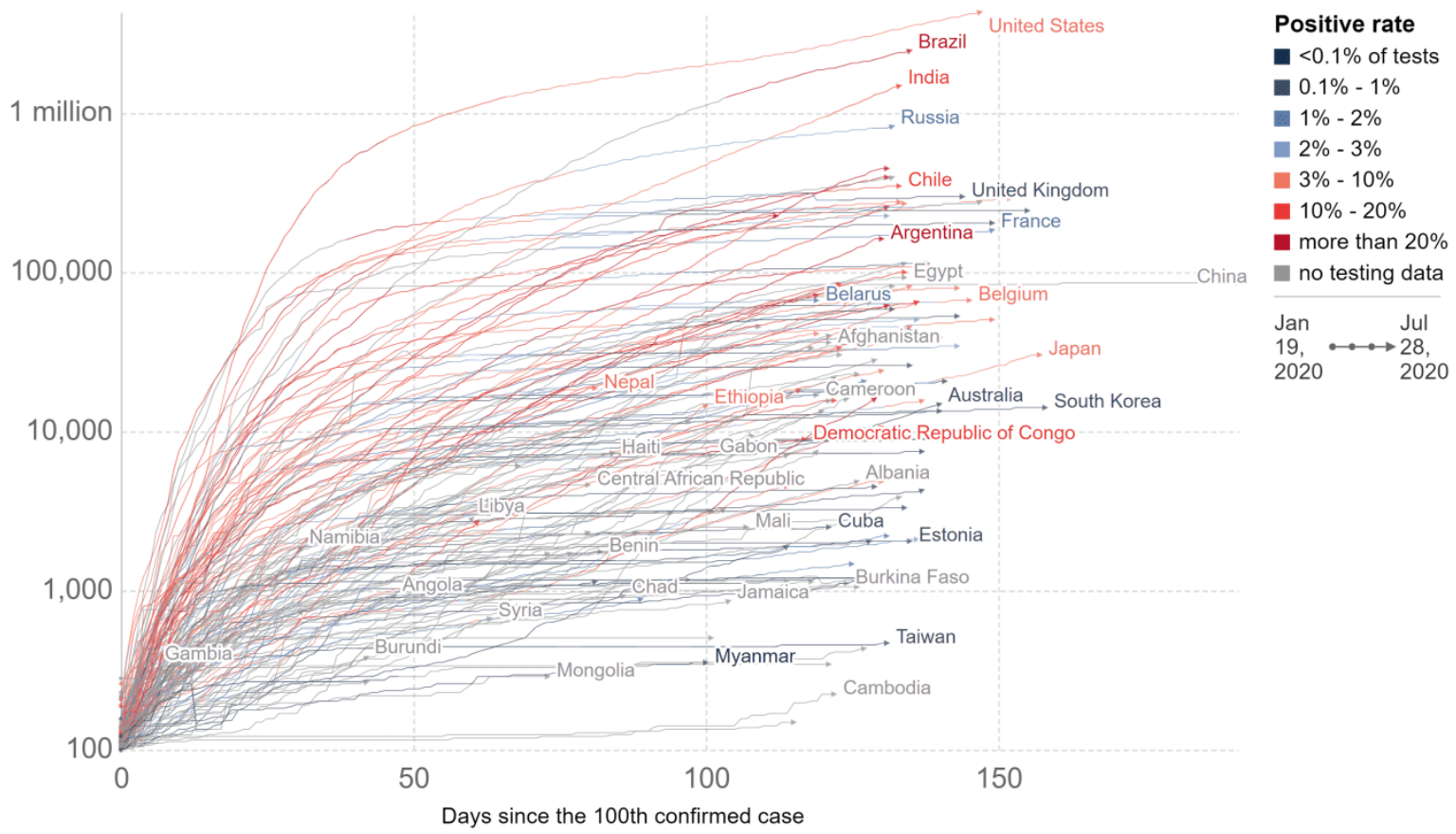

Source: European CDC - Situation Update Worldwide - Last updated 28 July, 11:07 (London time), Official data collated by Our World in Data CC BY 
ANEXO 2

Óbitos acumulados de COVID-19 por Semana Epidemiológica de notificação

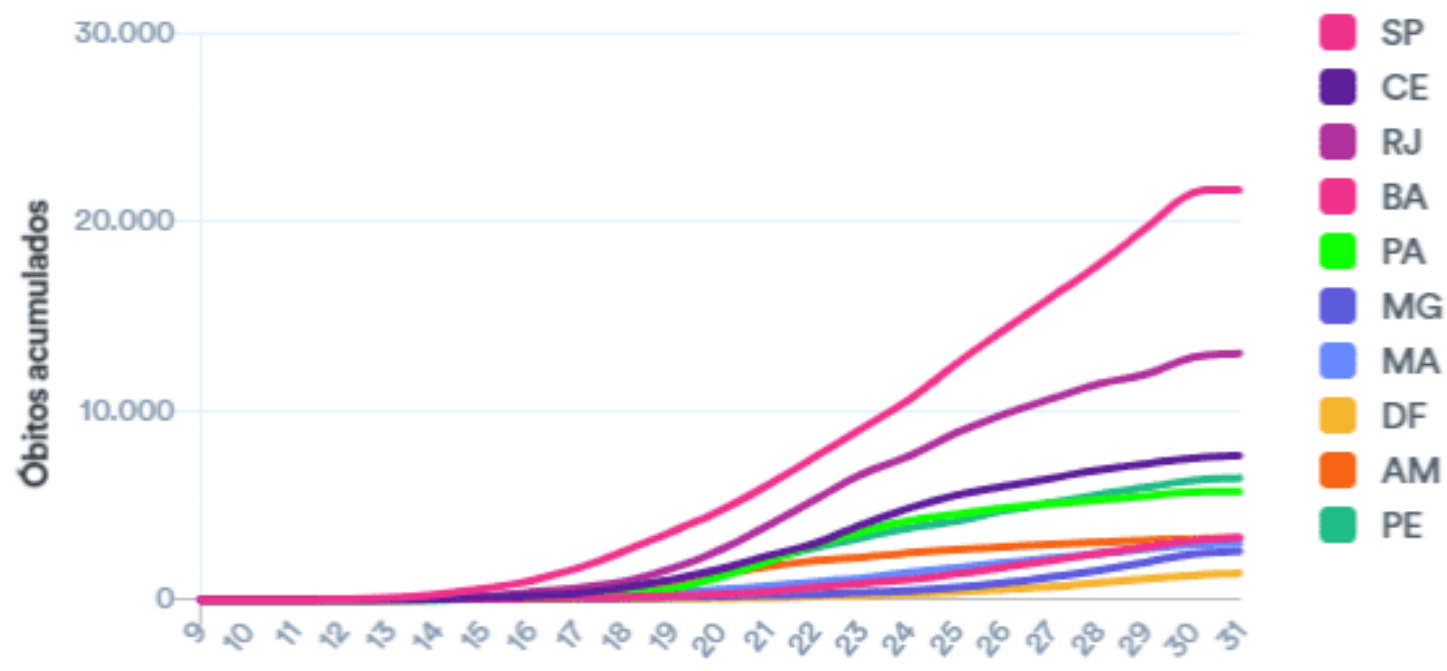

Semana da notificação

Fonte: Secretarias Estaduais de Saúde. Brasil, 2020

Enviado: Julho, 2020.

Aprovado: Agosto, 2020. 